\title{
Understanding lean \& safety projects: analysis of case studies
}

\author{
Maria Crema1 and Chiara Verbano ${ }^{1 \star}$
}

\begin{abstract}
Facing the current socio-economic contingency while guaranteeing a high level of care quality is particularly challenging in the field of healthcare. Through an integrated adoption of emerging managerial solutions, projects that allow organizations to achieve both efficiency and patient safety improvements could be implemented, thereby transposing policy directives towards a safer and more sustainable healthcare system. Therefore, the purpose of this paper is to investigate the features of Lean \& Safety (L\&S) projects. Three Health Lean Management (HLM) projects that had unexpected patient safety results were selected from the same region. Differences and similarities among the cases have been highlighted and interesting points of evidence have been noted. Despite the fact that the projects were pursuing similar objectives and benefiting from comparable support, the obtained changes had direct impact on patient safety enhancement in the cases that involved the front-office processes, and an indirect impact on patient safely for the L\&S project that focused on back-office activities. The implementation processes and the Information and Communication Technologies (ICT) adoption of the cases are also different.
\end{abstract}

Keywords: healthcare management; Health Lean Management; Clinical Risk Management; Lean \& Safety projects; case studies.

Submitted: August $29^{\text {th }} 2017$ / Approved: November $21^{\text {st }} 2017$

\section{Introduction}

In the current macroeconomic situation, healthcare spending is difficult to afford, especially in countries where healthcare is funded partially or completely by government. All expenditures for public services, including healthcare, have been questioned and reduced. At the same time, risks in healthcare have been increasing, and insurance companies are not prepared to provide the right solutions for solving the problems. Nonetheless, quality levels have to be guaranteed not only for obtaining accreditations, but also for complying with challenging ethical issues. In this challenging context, new solutions for service operations and management are required in order to manage healthcare in a more efficient and effective way, thereby reducing healthcare wastes and, at the same time, improving quality of care and patient safety. In several cases, the main obstacles for providing timely and accurate treatments and therapies relate to managerial issues, rather than clinical ones (Bensa et al., 2010). This leads to a lack of synchronization among the actors of the hospital, which causes overcrowding in the emergency department, bed shortage, delays, lack of proper materials and equipment, high costs, waste, errors (both administrative and clinical), excessive workload, and inappropriate care settings, which all negatively affect medical care. Advanced Operations Management models, such as Health Lean Management (HLM) (Womack \& Jones, 2003) could be developed in health care settings in order to control process variability and to ensure a strategic alignment in the organization, thereby achieving the competitive advantages defined in the company's strategy (Slack \& Lewis, 2002; Hines et al., 2004). Other managerial approaches towards quality improvement, such as Clinical Risk Management (CRM), could also support the increasing of care quality. A methodology that combines HLM and CRM is missing in the literature (Crema \& Verbano, 2013), even though it could be a potential solution for obtaining simultaneous efficiency, effectiveness, and safety enhancements. For this reason, the first studies in the literature have analysed "Lean \& Safety" (L\&S) projects, which are defined as HLM projects that report patient safety improvements (Crema \& Verbano, 2015); however, their features deserve to be deeply investigated. For this reason, the purpose of this paper is to investigate the key managerial and organizational aspects of L\&S projects that were developed in the same regional context. In the following section, the theoretical background will be synthesized. Then, the research objective will be explicated and the methodology will be described. Afterward, the results of the analyses will be reported and they will be compared with the literature, and then the conclusions of the paper will be outlined, along with their implications for future research.

\section{Theoretical background}

Quality of care can be defined, evaluated, and improved differently, according to the diverse perspectives of the interested stakeholders. One study defined it as "consistently delighting the patient by providing efficacious, effective and efficient healthcare services according to the latest clinical guidelines and standards, which meet patient needs and satisfies providers" (Mosadeghrad, 2013, p.215). The adoption of a single managerial approach does not seem to be enough to simultaneously improve the efficacy, efficiency, and effectiveness of care quality. A poor level of care is often due, not to the laziness and incompetence of the healthcare staff, but rather to systems that are not adequately projected and managed (Reason, 2000). Over time, approaches to quality management have become more proactive in healthcare, as in many other sectors, with a focus on designing and adopting quality systems that aim to reduce the possibility of errors. From the perspective of quality control and assurance, many organizations have implemented Total Quality Management (TQM), where

(1) Department of Management and Engineering, University of Padova, Stradella San Nicola 3, 36100 Vicenza - Italy.

*Corresponding author: chiara.verbano@unipd.it 
everybody, at any level of the firm, has to be involved and provide a contribution to quality management, thereby pursuing excellence. However, according to Bohmer and Ferlins (2006), TQM was problematic due to its emphasis on a hierarchical control on the processes that occurred at the top levels of management, and by the extreme rationalization required for every decision. Other approaches were not suitable for a healthcare organization. In particular, Six Sigma was a purely statistical methodology that allowed for a small percentage of errors, but was still unacceptable for healthcare. Traditional quality management initiatives, such as quality control, quality assurance, and Six Sigma, assume a retrospective approach and are not applicable to the entire system, and it seems that they do not lead to a proper reduction and prevention of errors (Herring, 2009; Schwappach, 2011; Berte, 2004). Currently, process management provides the basis for advanced quality management, and the methodologies that have been considered thus far are Business Process Reengineering, Business Process Improvement, Lean Management, and Lean Six Sigma. In particular, Health Lean Management aims to develop a hospital culture that is characterized by increased satisfaction through continuous improvements, in which all employees actively participate in identifying and reducing non-value-adding activities (i.e. waste) (Dahlgaard et al., 2011). The definition of value in healthcare should be linked to the attributes identified for quality of care (Arah et al., 2006; Mosadeghrad, 2013); among these, the most recognized are accessibility, safety, efficiency, equity, and effectiveness. Clinical Risk Management should also be performed starting from the stage of process analysis, according to its system approach. Only in this way it is possible to develop defensive systems and processes to detect, prevent, and avoid errors.

Risk Management in a health care context can be defined as "an organized effort to identify, assess, and reduce, where appropriate, risks to patients, visitors, staff, and organizational assets" (Kavaler \& Spiegel, 2003, p.3). CRM is a particular kind of risk management that focuses on clinical processes that directly or indirectly involve patients. It includes the organizational structures, processes, instruments, and activities that enable hospital employees to identify, analyse, contain, and manage risks while providing clinical treatment and patient care (Walshe, 2001; Briner et al., 2010). CRM is often deemed to be the opposite of HLM, because it is focused on identifying and managing risks, rather than eliminating waste and aiming to improve efficiency. The latter is a typical objective of HLM, which aims to eliminate all the waste and all the obstacles that hinder the flow of the analysed process. The focus of the two managerial approaches seems conflicting. However, in a healthcare organization, risks should be managed and prevented and, at the same time, efficiency enhancement is required by diverse external pressures, as aforementioned. To this extent, a methodology that combines HLM and CRM could permit the development of new solutions that would reach multiple objectives. In the literature, L\&S projects that focused on patient safety improvement objectives have recently been studied (Crema \& Verbano, 2015). However, there are no studies that investigate whether and how L\&S projects can lead to patient safety improvements, deliberately pursuing only increases in efficiency. Although Waring and Bishop (2010) underlined the perplexities and struggles with the translation of lean management practices into the clinical practice, this approach has demonstrated interesting results, mostly in terms of productivity, cost, and timely care delivery, but also in patient care improvement (Toussaint \& Berry, 2013; Kollberg et al., 2006). According to McDermott and Venditti (2015), learning about the effectiveness, tools, and practices of lean management in a knowledge-based work environment needs to be increased. As the settings are different from the manufacturing industry, the key elements required for a successful project implementation could vary. In particular, the peculiar characteristics of the knowledge-based work environment with regards to task uncertainty, process invisibility, and architectural ambiguity, are particularly evident in front-office operations, rather than in back-office ones (McDermott \& Venditti, 2015; Staats et al., 2011). As emphasized by McDermott and Venditti (2015), specific contextual variables impact the effectiveness of the HLM. Aiming at developing integrated value streams, HLM destroys the professional boundaries within which employees are used being in; in this way, HLM influences the social organization of healthcare (Waring \& Bishop, 2010; Joosten et al., 2009). Several authors denoted the paucity of research on human elements of HLM adoption, such as motivation, team working, training, empowerment, and respect for people, which constitute the key factors for the long-term sustainability of any lean programmes (Yang et al., 2012; Hines et al., 2004). For this reason, in the current study, these dimensions are part of the analysis framework, in which operational improvements, outcomes of quality of care, an overall focus on patient safety, impacts on organizational climate, and employee satisfaction have been included. As Joosten et al. (2009) highlighted, all these aspects are rarely considered together and the sociotechnical effects of HLM are neglected, even if HLM should favour employee well-being. In particular, top managers should support HLM in order to develop an environment where collaboration and teamwork permit the achievement of higher performance levels than those achievable by a single person. Hospital managers, at senior and local department levels, should become leaders and facilitators of HLM and they should be sufficiently trained on Lean Thinking, in order to involve and enrol other clinicians and enact changes (Toussaint \& Berry, 2013; Waring \& Bishop, 2010). As demonstrated by Waring and Bishop (2010), if people are not involved they will often comply with the new procedures, but only in a superficial way, without demonstrating a profound conversion, and they will often return to the previous situation or procedure as soon as possible. Therefore, in the cases analysed in the current research, the support of top management and employee involvement will also be investigated. Moreover, in each phase of the project implementation process, the adopted tools and practices will be identified in order to understand those that can be adopted in an L\&S project. In the literature, phases of HLM implementation are suggested by Poksinska (2010). In other cases, the steps of a Root-cause analysis and quality management system, such as PDCA (Plan-Do-Check-Act) are followed (e.g. Amin, 2012). Nevertheless, the implementation process of L\&S projects has been never developed, and thus, it will be rebuilt for the following three investigated cases through analysis 
of the collected data, responding to the needs of theory, which will guide the expectations of the possible effects of HLM (Shah \& Ward, 2003), in particular those of L\&S projects.

\section{Objectives and methodology}

The purpose of this paper is to compare the main characteristics of $L \& S$ projects in different contexts that are affected by the same regional policy that fosters HLM principles. Considering that there are few studies on L\&S projects have patient safety enhancement as an objective, HLM projects that reported unexpected safety improvements were selected. In particular, three cases from two hospitals (Alpha and Beta) have been chosen; two of them concern front-office processes, while the other is focused on back-office processes. The cases come from similar fields of application, which support literal replication (Yin, 2009). After defining a designed research protocol (Saunders et al., 2009; Yin, 2009; Voss et al., 2002) to assure the analysis reliability, a key informant for each hospital was contacted and informed about the research project. From this contact, snowball sampling took place, and the most appropriate people to interview were identified (Harris et al., 2009). In order to assure the research validity, transcripts of the semi-structured interviews were triangulated with data from web sites, reports, internal documentation, and archival records (provided by hospitals or gathered online) (Eisenhardt \& Graebner, 2007; Yin, 2009), as reported in Table 1, where the information about the role of the interviews can also be found.

Table 1. Information about data collection

\begin{tabular}{|l|l|l|l|l|}
\hline CASE & FIELD OF APPLICATION & TYPE OF HOSPITAL & DATA COLLECTION & Other Sources \\
\hline NV2SI & Emergency dept. & University hospital & $\begin{array}{l}\text { Economist lean specialist and a } \\
\text { nurse (staff of HLM unit) }\end{array}$ & $\begin{array}{l}\text { Internal documentation and reports about the proj- } \\
\text { ects and the HLM experience, documents from the } \\
\text { hospital website }\end{array}$ \\
\hline SIMED & Internal medicine & University hospital & $\begin{array}{l}\text { Two management engineers } \\
\text { (HLM unit staff })\end{array}$ & $\begin{array}{l}\text { Internal documentation and reports about the proj- } \\
\text { ects and the HLM experience, documents from the } \\
\text { hospital website }\end{array}$ \\
\hline $\begin{array}{l}\text { PROJECT } \\
\text { BETA }\end{array}$ & Medicine dept. & Hospital of LHU & $\begin{array}{l}\text { Economist and management } \\
\text { engineer (staff of HLM unit) }\end{array}$ & $\begin{array}{l}\text { Initial meeting with a brief presentation of the proj- } \\
\text { ect and interventions of the general director, docu- } \\
\text { ments from the hospital website }\end{array}$ \\
\hline
\end{tabular}

Following a defined research framework (Crema \& Verbano, 2015), several features were analysed, including organizational aspects, triggers and objectives of the project, phases followed, activities adopted, tools and techniques, outcomes, and enabling and hindering factors of the project implementation. After the coding and category creation was completed, a uniform variable matrix was developed in order to report the results of the within-case analysis (Miles \& Huberman, 1994). The adoption of the same framework permitted the development of three tables with the same format, allowing for a simple comparison of the three cases according to the most relevant variables.

\section{The context of hospital Alpha}

Two L\&S projects were selected from a hospital (Alpha) that began to adopt HLM in 2012. Alpha is a highly specialized Italian university hospital, a centre of teaching and research, built many years before 2000. With approximately 800 beds and 3,000 employees it provides basic local and specialized services for about 120,000 and 250,000 citizens respectively. The presence of the Medicine Faculty adds additional national and international value to this hospital, especially in relation to the specialized services, which increase the number of potential patients that can access the hospital.

The mission of the hospital is to assure the highest possible level of health care, reconciling research and teaching, and making the organization comparable with the most prestigious university hospitals.
Another aspect of the mission relates to the integration of its structure with the surrounding community in order to guarantee continuity of assistance, and the creation of a climate of internal collaboration that emphasizes the principles of professionals' valorisation and mutual respect. Listening, information, and support are offered to patients in a service that has to be global, personalized, safe, and evidence-based. One of the hospital objectives is to improve the service level through high professionality and specialization, providing a service that has value for the patient in a safe and comfortable place, and which integrates a high level of clinical assistance with attention to human and relationship aspects. Therefore, the patients are at the centre and pathways have to be developed according to their needs.

The hospital is organized into eight departments, and three separated units of staff work under the hospital director and are in charge of HLM, CRM, and quality. Since the first adoption of HLM, more than 30 projects have been implemented, also thanks to a yearly competition that awards the best projects developed inside the hospital. Moreover, the HLM unit has been providing HLM training courses at different levels (more than 300 people are already trained) in order to create an efficient and collaborative work environment that has to be continuously improved and in which waste is eliminated through adoption of HLM. So far, the realized projects aim mainly to reduce time, costs, movement, space, and defects not directly linked to patients (e.g. errors occurring from reading bad handwriting), but there are also new projects whose objectives aim to reduce inappropriate 
services and or deal with patient satisfaction. However, the HLM unit seems to not be integrated with CRM, which was not involved in the two projects analysed in this research. In addition, the quality unit was not involved even though, among other things, it had to accredit the procedures required for HLM adoption. In general, the quality department uses audits, checklists, and questionnaires to monitor adherence to defined standards, and it supports the definition of assistance pathways. Beginning from quality evaluations performed by the quality department, improvement actions can be requested and carried out by the interested unit. Moreover, the hospital follows the institutional accreditation, ISO 9001, and the accreditation for providing Continuous Medical Education.

\section{The context of hospital Beta}

One of the projects was selected from a hospital of a Local Health Unit (LHU) that was built more than 15 years ago. With more than 2,500 employees and approximately 500 beds, it serves a catchment area of approximately 200,000 inhabitants. The LHU intends to guarantee, among others, the principles of:

- centrality and participation of the citizen;

- universality and equal access and Essential Assistance Levels that are managed by a unique healthcare system and financed by public funds;

- institutional subsidiarity and full involvement of local authorities in the policies of health promotion;

- free choice of the place where one is to be cared for;

- professional evaluation of employees.

In particular, reflecting the objectives of its regional authority, it aims to improve the healthcare and the well-being of the population, satisfaction and participation of citizens, and efficiency and sustainability of the system. It has also started to redefine its assistance settings according to the intensity of a care-based model, which has involved reorganizing the surgery and medical areas, developing a model of assistance continuity through integration of the hospital with the other healthcare organizations distributed in the territory, and defining the roles of medical tutor and referent. This LHU has reported excellent results in terms of quality of the healthcare processes, especially in demonstrating the existence of adequate diagnostic and therapeutic pathways shared between emergency department and inpatient wards. Moreover, due to integration between the hospital and the other healthcare organizations in the territory, the hospitalization rate for this LHU is lower than the regional mean. The management of admissions and discharges is evaluated using measurement indicators such as hospitalization rate, discharge rate, and percentage of hospitalizations of over 30 days.

The above-mentioned results were obtained in an organizational structure that includes three units in staff who work under the general hospital director: the quality and accreditation unit, the CRM unit, and the HLM unit. There is no integration among these units, even though the clinical risk manager has required at least some integration between CRM and the quality and accreditation unit. The latter unit deals with all the activities concerning institutional accreditation, maintenance of the quality book, and procedures regarding the general management. This LHU is also strongly committed to implementing procedures for reducing clinical risks. The CRM unit executes audits (e.g. for adverse events with the highest impact, frequency, and difficulty in being detected), verifies the adoption of good practices, assures the application of regional and national recommendations, and oversees the encouragement of preventive actions and monitoring of activities. Furthermore, it draws up a plan, a budget, and a final report. In addition to checking the execution of best practices, monitoring compliance with protocols and procedures or guidelines, and application of the ministerial recommendations, the hospital Beta uses reference standards and compares the results with the available literature. Beta analyses claims and incidents, studies errors, adopts incident reporting including the Mortality \& Morbidity review, structures the registration of information for the patient, obtains consent, performs auto-evaluation, monitors the medical records, manages litigation, and utilizes check lists for the operating room.

Since 2012, there has been a simply structured team that manages HLM projects in the LHU.

The key strategic aspects of the two hospitals are reported in Table 2

Table 2. Key strategic aspects of the interested hospitals

\begin{tabular}{|c|c|c|}
\hline key strategic aspects & Alpha & Beta \\
\hline $\begin{array}{l}\text { Alignment with customer needs and expectations/ per- } \\
\text { sonalization/ value for customer }\end{array}$ & $\mathrm{X}$ & $\mathrm{X}$ \\
\hline $\begin{array}{l}\text { Offer of comprehensive, personalized, safe and evi- } \\
\text { dence-based healthcare }\end{array}$ & $\mathrm{X}$ & \\
\hline Continuity of care & $\mathrm{X}$ & \\
\hline $\begin{array}{l}\text { Listening, informing and comforting patients and family } \\
\text { / considering relational and human aspects }\end{array}$ & $\mathrm{X}$ & $\mathrm{X}$ \\
\hline $\begin{array}{l}\text { Being financially sustainable/ resource cheapness/ effi- } \\
\text { cient }\end{array}$ & & $\mathrm{X}$ \\
\hline $\begin{array}{l}\text { Development of a work environment that favour opera- } \\
\text { tors (safe and comfortable environment) }\end{array}$ & $\mathrm{X}$ & \\
\hline Development of a climate of internal collaboration & $\mathrm{X}$ & \\
\hline Reduction of the assistance variability & & $\mathrm{X}$ \\
\hline
\end{tabular}

\section{Results from the three case studies}

\section{Project Alpha 1}

The first project selected in Alpha was implemented in the emergency department.

The emergency service manages about 50,000 patients per year. Thanks to regional funds, this project was implemented in order to improve patient flow and reduce waiting times, thereby enhancing patient service. The regional authority was a financial and technical supporter of this project, and therefore no external consultants were included on the project team, which consisted of people from the HLM unit who were already trained. Another relevant support 
came from the hospital director, who believes in HLM and has experience with this new managerial approach. The project team consisted of members of the HLM unit, members of the management audit, a medical referent, an operator, and a member from the data processing centre. As is detailed in Table 2, after a planning phase, a training course of four hours was provided to all the employees of the emergency department. Other hospital staff and patients were informed through an article in a periodical journal and through leaflets distributed inside the hospital.

Afterwards, patient processes were identified and analysed, and, in particular, critical issues, value added, and no-value-added activities were recognized. Thus, HLM tools were adopted, including one-piece flow, visual management, checklist, triangulation, fast track, facilitated paths, 5S, layout change, and organization of workstations for the process optimization. Feedback was gathered from questionnaires that were sent to the operators, and also through economic indicators, indicators related to the organizational system and to the "muda", indicators from MeS (Management and healthcare - "Management e Sanità": an Italian laboratory) that were collected in a managerial dashboard. Feedback from patients was obtained through the MeS questionnaire. Efficiency increase was reported, and, indirectly, the care appropriateness was improved through the reduction of exams executed more than one time. Moreover, since they were spending less time in the emergency department, patients were less exposed to risk of infection. Without using sophisticated ICT or other additional resources, the work climate improved, spreading among the operators a feeling of trust, involvement, and freedom to express their own opinions. Some of the aspects that were recognized as facilitating the implementation of the project were the support of the top management, the continuous presence of the team in the field, and the utmost respect for the operators' experience by the HLM team. These factors permitted the realization of the project despite the low level of HLM training of the operators and the difficulties surrounding information exchange, which occur mostly due mostly to the changing work shi$\mathrm{fts}$, the absence of data reporting, the institutional bureaucracy, and the mind-set of physicians that is still linked to their traditional way of working. In order to guarantee the sustainability and continuity of HLM adoption, in addition to time spent in the ward and the organization of meetings with people from other departments, training was considered to be fundamental, since it extends the HLM culture.

\section{Project Alpha 2}

Some of the interviewees considered this project as a continuation of the previous one. It was realized in internal medicine due to the input of regional funds. Like in the previous case, external consultancy was not deemed useful due to the existence of internal HLM competences. The team was constituted of nine people who were involved with the staff of the HLM unit, two members of the ward, the head nurse, and a nurse. Part of the team was, at the beginning, engaged with the project on a full-time basis. Training was provided first to the team members and then to all the people of the ward through an initial training course and periodical meetings. The latter were organized at the beginning to inform and train the referents and operators, during the project to deal with individual issues and to obtain opinions and suggestions from operators, and at the end to monitor and communicate the results. As is noted in Table 3, the objectives of the project included optimization of the process flow in order to reduce the average length of stay and consequently the costs, the improvement of communication between physicians and nurses, and the achievement of an image of high quality. These objectives were pursued through adopting different HLM tools. After a planning phase and the identification and analysis of the process of a typical patient, the two members of the first medicine area that was involved drew the Value Stream Map with the HLM staff, in order to better understand the context in which they worked.

Afterward, the participants from the other two areas that comprise internal medicine were involved in order to define the legend and the panel to be used for planning the patient service. After informing all the ward staff and after simulations, the defined tools were adopted by operators. Visual management, one-piece flow, $5 \mathrm{~S}$, check list, fast track and Heijunka were adopted, in addition to a plan for every patient. Through these HLM tools, efficiency improvements were obtained. The achieved results are monitored monthly, measuring the mean of the length of stay and its statistical dispersion, the use of the discharge room, and other indicators for admissions, discharges, and the planned activities, as reported in Table 3. In particular, because of this project, it was possible to reduce the average length of stay, to care for patients in a shorter time frame, and to enhance the management of discharges. One of the most significant results is in relation to the reduction of potentially inappropriate DRGs (DiagnosisRelated Groups) which, according to Fetter et al. (1980), permit the classification and management of hospital cases based on diversifying variables. A better, well-organized environment has led to decreased downtime and fewer useless complications and organizational causes that delay the discharges. Moreover, operators now work more calmly, thereby indirectly reducing the risk of erring. In the operator survey, briefing was considered useful and communication among practitioners seemed improved. Moreover, now operators share the patient process and feel themselves to be an active part of the care pathway.

These outcomes were obtained with no additional resources and with only a few organizational changes, such as the briefings managed by the head nurse. One of the project enabling factors was the continuous presence of HLM team on the field and the team's availability, listening efforts, and ability to collaborate with operators without interfering with their daily work, and their leaving the final decision to the ward. Other key factors for the success of the project were the training course, the sharing with the organization, the support of the top management, and the adoption of a clear concept of planning. Closed mind-sets and resistance to change, lack of support from the head physician, lack of information/data, and of the use of information systems were recognized as hindering factors.

In order to sustain HLM adoption, training is considered fundamental for extending the right culture, in particular including "cascade training" (Jacobs, 2002). Moreover, it is important to transmit the 
following concept: lean valorises the operator and the support of the HLM team serves to guarantee the continuity of the project.

\section{Project Beta}

Different external experts have provided HLM training courses to the staff of hospital Beta, constituted by people with diverse roles, such as physicians, nurses, directors. Therefore, no external consultants were involved in the examined project. For some years, the LHU has been working on a unique large project, with the intention of integrating different productive platforms. The first single project activated in the medicine department began in a context of economic and financial resource reduction, in which the community requested that the department guarantee at least the same level of service for the patients and adopt new tools for process optimization and for hospital performance evaluation. The project started with the aim of optimizing the patient flow, guaranteeing a continuous flow and reducing process variability due to organizational inefficiencies, and reducing the average length of stay. Favoured also by the opening of the hospital in a new place and the reorganization of services and revision of internal processes, other project objectives were: elimination of local sub-optimizations through process governance with system logics, involvement of all the staff, multidisciplinary and multi professional integration, simplification of processes/activities, and efficient and appropriate use of resources.

The project was entrusted to a new unit (HLM unit) that was dedicated to it on a full-time basis. The hospital director, who believes in HLM, supported the project, provided the strategic direction, and made all the necessary resources available. The first phase of the project realization was the demand analysis. As detailed in Table 4, after the study of the patient process, the critical issues were identified and analysed, including, for instance, the information exchange and the practitioners' agenda. The priority of interventions was defined with the hospital director and a testing phase was executed, simulating the sought screen on paper. People with different roles and diverse backgrounds were involved, first of all through a training lesson at the beginning of the project, followed by ongoing coaching on the field realized through close contact with the HLM team, especially during the first four days. Using the software ADT (Admission, Discharge, Transaction), beds are now managed through computerized visual management. Results are also continuously monitored through a dashboard with indicators, information about bed occupancy, use rates, waiting and response times, residual production capacity, system of process alerts, real-time representation of the work plans, and average length of stay. The latter has moved from -0.17 to -0.52 days in respect to the previous year. The implemented system allows for more transparency. Before the project implementation, there were often no available beds at the time of a patient's admission, and now there are 10-15 vacant beds. Moreover, the problem analysis has been improved and duplications reduced, as the nurse does not have to transcribe the patient data more than one time, thereby decreasing time for this activity and limiting the potential for error. Everything is computerized, thus it is not necessary for a person to physically be in a place, and phone calls are not required. From all of this, in addition to creating simplification from a bureaucratic and administrative point of view, there is a simplification and a learning process of many activities: the inpatient unit is managed in the emergency department by a unique manager of emergency admissions (a physician), discharges are performed in " 3 clicks" and beds are managed in " 2 clicks". Furthermore, employees have direct access to the area of labels and bracelets printing. Consequently, the patient flow is also more rapid. With only a few organizational changes, transparency has increased and collaboration between operators and the HLM team has been introduced.

Moreover, even if not all the staff have accepted the changes, those who took part actively in the project are now satisfied with it. The elements that enabled the project include the use of ADT, which was already known in the hospital, the support of the top management, a system view of the interventions, the numerous contacts of the HLM team that included operators with a strong sense of motivation and determination. Nevertheless, there were also hindering factors. The first one was the resistance to change, as "it is difficult to change the organizational behaviour" (according to an interviewee). There are professionals who still struggle to accept the changes, especially those who have lost part of their control. Moreover, HLM procedures are still not properly defined and there are not shared accreditation standards to be followed for assuring the development of a quality system based on HLM. Therefore, defining HLM standards and procedures inside the hospital by the quality unit is not always easy and foregone.

However, the examined project is the first of a series of planned projects that will be realized in this LHU. The integration of all the projects using a unique software package is a way of guaranteeing the continuity and sustainability of HLM. Other tools and practices to be adopted in relation to this are: training courses, contacts with operators, continuous refreshes and recalls of HLM information, the execution of cyclic activities thanks to PDCA, but mostly the motivation of the team in charge of the realization of HLM projects.

\section{Discussion of the results}

All the three analysed projects were supported by the regional authority and they pursued efficiency objectives. The emphasis of the interested regional authority on HLM adoption is evident and it emerges from the analysis of its Regional Health Plan, as well as from the analysed projects and from the strategic direction of their hospitals that are working to put into practice the transposed regional directives. Other similar features have to be emphasized. First of all, the projects demonstrate analogous hospital organizational characteristics. In particular, a unit dedicated to HLM exists in both of the hospitals and CRM is not involved in the projects, except for at the end of the project Beta, where the clinical risk manager was consulted after the reporting of the first results. The role of the HLM unit was fundamental for the implementation of these projects. The staff of those units included people without a medical background. Consistent with McDermott and Venditti (2015), the involvement of people who are not involved on a daily basis with the clinical activities can be crucial, in order to design the clinical activities according to a process logic and 
then to identify problems. In addition to the commitment and the availability of the HLM team and the employee participation, the support of the top management was crucial. As has been demonstrated by some scholars who study quality management and HLM (Dickson et al., 2009; Lagrosen et al., 2007), leadership and commitment of managers are required to achieve effectiveness and efficiency improvements. In all the analysed cases, the hospital director had previous HLM experience and he strongly believed in it. Thanks to the existing internal competences of HLM and the regional community, which provides also technical support if requested, no external consultants were required for the project's success. In addition to similar efficiency objectives, in the second and the third cases there is a need to improve the communication between people with different roles in the hospital. In these projects, the project team intended also to improve the hospital's image and the focus on patient needs. A challenging change management was ascertained in all the projects. As emphasized by McDermott \& Venditti (2015), in a knowledge-based work environment, employees are often afraid of cost-cutting and efficiency increases, an attitude that worsens patient care and safety. For this reason, training courses, staff involvement and all the initiatives to diffuse the culture of quality improvement should be encouraged inside the hospital. However, similar results were obtained in terms of efficiency, internal collaboration, and communication improvements, especially for the second and third cases. In particular, trust in the HLM unit was increased after the realization of the projects.

On the contrary, there are different characteristics regarding the implementation process, the ICT adoption, and the processes to be improved. As concerns the latter, the processes were for the front-office in the first two cases, as they were visible to patients, while in the last project the attention was focused on the flows of material and patient information, and on employees' well-being, which indirectly impacts patient care. In particular, as noted by McDermott \& Venditti (2015), by reducing time wastage, hospital staff have more time to be dedicated to patients. However, the projects report dissimilar results concerning patient safety; for instance, only in the first two projects were reduction of infection risks and potentially inappropriate DRGs declared. In the third case, the reduction of errors was mostly in relation to the transcription of patient data and the simplification of the practitioner work, issues that have an indirect impact on patient safety. Considering the factors categorized by Vincent (1998), in the analysed cases, errors can be prevented by removing any issues that relate to: team factors (especially concerning verbal and written communication), task factors (in particular for task design), work environment (mainly for administrative and managerial support), and organizational and management factors (concerning financial resources and constraints, organizational structure, policy standards, and goals). In the investigated cases, adopting HLM permitted the hospitals to improve these factors that affect the clinical practice. At the same time, the latter is influenced also by the economic and regulatory context, which in the examined region fosters HLM adoption.

Considering the implementation process, there are similar phases, even if they are positioned in different sequences. For example, the planning and the information and training phases were postponed in the third case, but they were also executed in the others. Demand analysis and definition of intervention priorities were recognized only in the project Beta, while the investigated flow was identified and mapped at the beginning of the project implementation in all three cases. In terms of ICT support, while in project Beta an electronic platform was designed, the interviewees of the second case claimed a need for information systems to support the realization of L\&S projects. Looking at the interesting results of the first two projects, the ICT adoption seems to be not fundamental for assuring project success. However, the potentialities of the third case are evident, considering the strategic aim, the final involvement of CRM and the ICT support, and they will be concrete when more attention is dedicated to the front-office processes: only through the improvement of them, it is possible to achieve direct patient safety improvements.

\section{Conclusion}

Even if some of the strategic aspects of the interested hospitals seem to foster the adoption of HLM, the approach adopted for continuous improvement could not still be defined an organization-wide philosophy; rather, according to the research of Øvretveit (2000), so far it has been implemented only as a set of methods for problem solving and process improving. However, the outcomes obtained in this study are significant and they have provoked a diffusion of HLM in the interested hospitals, in addition to improving the work conditions, and increasing staff communication and collaboration. In these projects, the presence of an HLM unit inside the hospital was considered fundamental for the continuity of L\&S projects implementation.

The investigated cases provide a contribution to the academic and managerial literature, reporting the organizational and managerial aspects of three L\&S projects. The sociotechnical elements have been analysed, together with the performance achieved in terms of quality improvement. The obtained results should be monitored in the future. Furthermore, in order to raise the generalizability of the reported study, the investigated L\&S projects should be compared with other cases developed in diverse hospitals, settings, and regions with a different Regional Health Plan. It could be also interesting to confront the characteristics of the cases with those of unsuccessful projects, looking at the problems that hinder the continuity of the project and the achievement of the defined objectives. The analysed L\&S projects constitute first experiences implemented in hospitals not used to HLM. However, they represent the first empirical experimentation of a research stream that aims to understand how, by adopting HLM, safety improvement can be obtained, and how a synergic methodology, which combines elements of HLM and CRM, can be developed to simultaneously enhance different attributes of quality of care.

\section{Biographical notes}

Maria Crema is Postdoctoral research fellow at Department of Management and Engineering of the University of Padova. Her main research areas are: innovation management and healthcare management. 
Chiara Verbano is Associate Professor of Management and Engineering Economics at the Department of Management and Engineering of the University of Padova. Her major research interests are the fields of risk management and innovation management.

Acknowledgements: The authors gratefully acknowledge the support from the research projects of the University of Padova CPDR147702.

\section{References}

Amin, A.N. (2012), "Strategies to optimize the prevention of venous thromboembolism: process improvement practices", Journal of Clinical Outcomes Management, 19(3), 117-124.

Arah, O.A., Westert, G.P., Hurst, J. and Klazinga, N.S. (2006), “A conceptual framework for the OECD health care quality indicators project", International Journal for Quality in Health Care, 18(1), 5-13.

Bensa, G., Giusepi, I. and Villa, S. (2010), La gestione delle operations in ospedale [Operations management in hospital], in Lega, F., Mauri, M., Prenestini, A. (eds.), Lospedale tra presente e futuro. Analisi, diagnosi e linee di cambiamento per il sistema ospedaliero italiano, Milano, Italy: EGEA s.p.a., pp. 243-288.

Berte, L.M. (2004), "Patient safety: Getting there from here-quality management is the best patient safety program", Clinical leadership \& management review: the journal of CLMA, 18(6), 311-315.

Bohmer, R.M.J. and Ferlins, E.M. (2006), Virginia Mason Medical Center, Boston, U.S.A.: Harvard Business School, Briner, M., Kessler, O., Pfeiffer, Y., Wehner, T. and Manser, T. (2010), "Assessing hospitals' clinical risk management: Development of a monitoring instrument", BMC health services research, 10(1), 337-348.

Crema, M. and Verbano, C. (2013), "Guidelines for overcoming hospital managerial challenges: a systematic literature review”, Therapeutics and clinical risk management, 9, 427-441.

Crema, M. and Verbano, C. (2015), "How to combine Lean and Safety management in health care processes: A case from Spain”, Safety Science, 79, 63-71.

Dahlgaard, J.J., Pettersen, J. and Dahlgaard-Park, S.M. (2011), “Quality and lean health care: a system for assessing and improving the health of healthcare organisations", Total Quality Management \& Business Excellence, 22(6), 673-689.

Dickson, E.W., Anguelov, Z., Vetterick, D., Eller, A. and Singh, S. (2009), "Use of lean in the emergency department: a case series of 4 hospitals", Annals of Emergency Medicine, 54(4), 504-510.

Eisenhardt, K.M. and Graebner, M.E. (2007), “Theory building from cases: opportunities and challenges", Academy of Management Journal, 50(1), 25-32.
Fetter, R.B., Shin, Y., Freeman, J.L., Averill, R.F. and Thompson, J.D. (1980), "Case mix definition by diagnosis related groups", Medical Care, 18(2), 1-53.

Harris, J.E., Gleason, P.M., Sheean, P.M., Boushey, C., Beto, J.A. and Bruemmer, B. (2009), "An Introduction to Qualitative Research for Food and Nutrition Professionals", Journal of American Dietetic Association, 109(1), 80- 90.

Herring, L. (2009), "Lean experience in primary care", Quality in Primary Care, 17(4), 271-275.

Hines, P., Holweg, M. and Rich, N. (2004), "Learning to evolve: a review of contemporary lean thinking", International Journal of Operations \& Production Management, 24(10), 994-1011.

Jacobs, R.L. (2002), “Institutionalizing organizational change through cascade training", Journal of European Industrial Training, 26(2/3/4), 177-182.

Joosten, T., Bongers, I. and Janssen, R. (2009), "Application of lean thinking to health care: issues and observations", International Journal for Quality in Health Care, 21(5), 341-347.

Kavaler, F. and Spiegel, A.D. (2003), Risk management in health care institutions. A strategic Approach, Sudburry Massachusetts (U.S.A): Jones and Bartlett Publishers.

Kollberg, B., Dahlgaard, J.J. and Brehmer, P.O. (2006), "Measuring lean initiatives in health care services: issues and findings", International Journal of Productivity and Performance Management, 56(1), 7-24.

Lagrosen, Y., Bäckström, I. and Lagrosen, S. (2007), "Quality management and health: a double connection", International Journal of Quality \& Reliability Management, 24(1), 49-61.

McDermott, C.M. and Venditti, F.J. (2015), "Implementing lean in knowledge work: Implications from a study of the hospital discharge planning process", Operations Management Research, 8(3-4), 118-130.

Miles, M.B. and Huberman, A.M. (1994), Qualitative data analysis: An expanded sourcebook, $2^{\text {nd }}$ edition, Thousand Oaks, CA: Sage Publications.

Mosadeghrad, A.M. (2013), "Healthcare service quality: towards a broad definition", International Journal of Health Care Quality Assurance, 26(3), 203-219.

Øvretveit, J. (2000), "Total quality management in European healthcare", International Journal of Health Care Quality Assurance, 13(2), 74-80.

Poksinska, B. (2010), “The current state of lean implementation in health care: literature review", Quality Management in Healthcare, 19(4), 319-329. 
Reason, J.T. (2000), "Human error: models and management", $B M J$, 320(7237), 768-770.

Saunders, M.N.K., Thornhill, A. and Lewis, P. (2009), Research Methods for Business Students, $5^{\text {th }}$ edition, Essex, UK: Financial Times Prentice Hall.

Schwappach, D.L. (2011), "Frequency of and predictors for patientreported medical and medication errors in Switzerland", Swiss Med Wkly, 141, w13262.

Shah, R. and Ward, P.T. (2003), "Lean manufacturing: context, practice bundles, and performance", Journal of Operations Management, 21(2), 129-149.

Slack, N. and Lewis, M. (2002), Operations strategy, Financial Times, Harlow, UK: Prentice Hall.

Staats, B.R., Brunner, D.J. and Upton, D.M. (2011), "Lean principles, learning, and knowledge work: evidence from a software services provider", Journal of Operations Management, 29(5), 376-390.

Toussaint, J.S. and Berry, L.L. (2013), "The promise of lean in health care”, Mayo Clinic Proceedings, 88(1), 74-82.
Voss, C., Tsikriktsis, N. and Frohlich, M. (2002), "Case research in operations management”, International Journal Of Operations \& Production Management, 22(2), 195-219.

Walshe, K. (2001), “The development of clinical risk management”, in Vincent, C. Clinical risk management: Enhancing patient safety, $2^{\text {nd }}$ edition, London, UK: BMJ Books.

Waring, J.J. and Bishop, S. (2010), "Lean healthcare: rhetoric, ritual and resistance", Social science \& medicine, 71(7), 1332-1340.

Womack, J.P. and Jones, D.T. (2003) Lean Thinking - Banish waste and create wealth in your corporation, New York, NY: Free Press.

Yang, C.C., Yeh, T.M. and Yang, K.J. (2012), “The Implementation of Technical Practices and Human Factors of the Toyota Production System in Different Industries", Human Factors and Ergonomics in Manufacturing, 22(6), 541-555.

Yin, R. (2009), Case Study Research: Design and Methods, $4^{\text {th }}$ Edition, Thousand Oaks (U.S.A.): Sage Publications. 


\section{Appendix: key characteristics of each project examined}

Fig. 1 Key characteristics of the "Lean \& Safety" project Alpha 1.

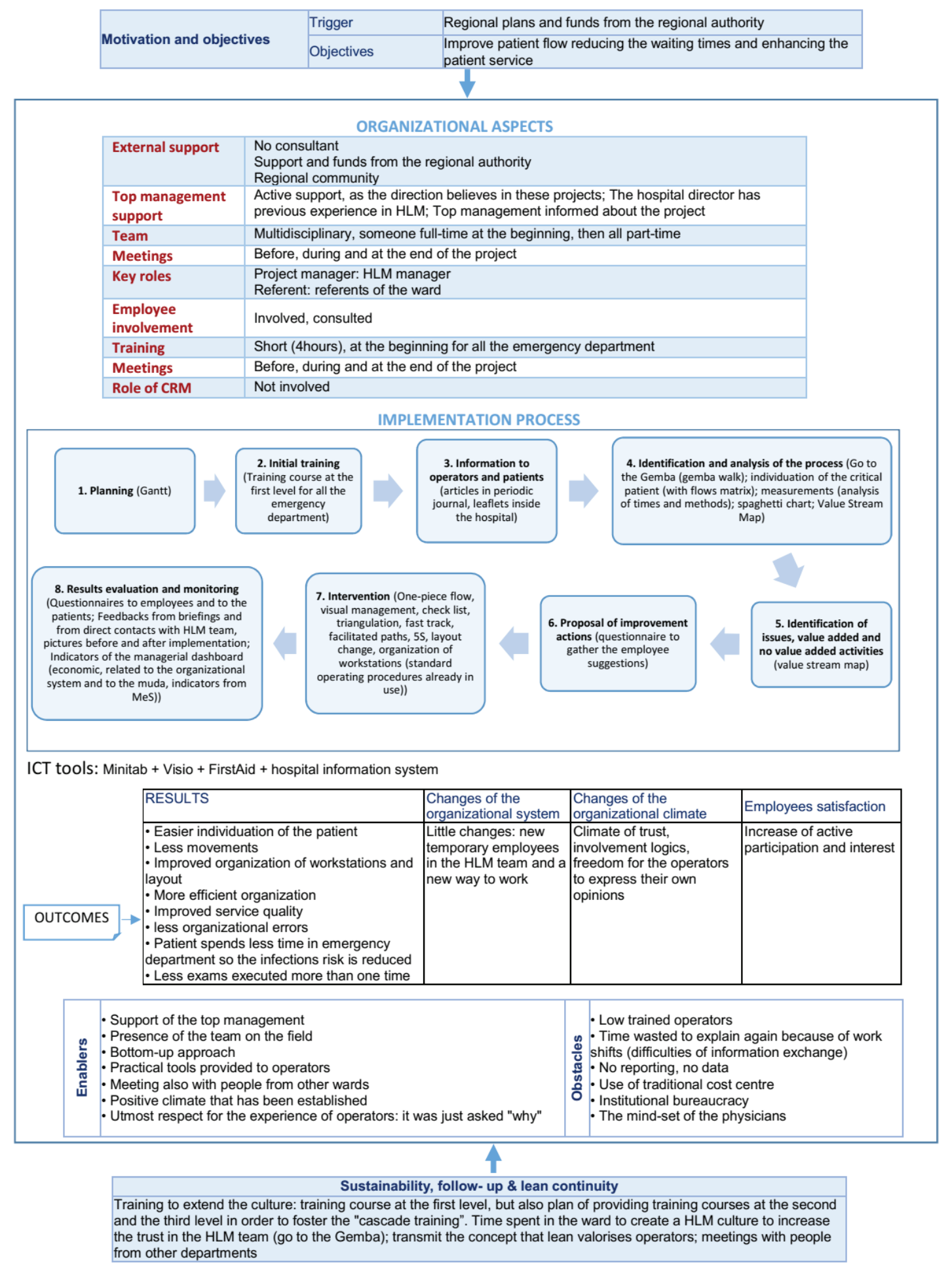

ISSN: 0718-2724. (http://jotmi.org)

Journal of Technology Management \& Innovation @ Universidad Alberto Hurtado, Facultad de Economía y Negocios. 
Fig. 2 Key characteristics of the "Lean \& Safety" project Alpha 2.

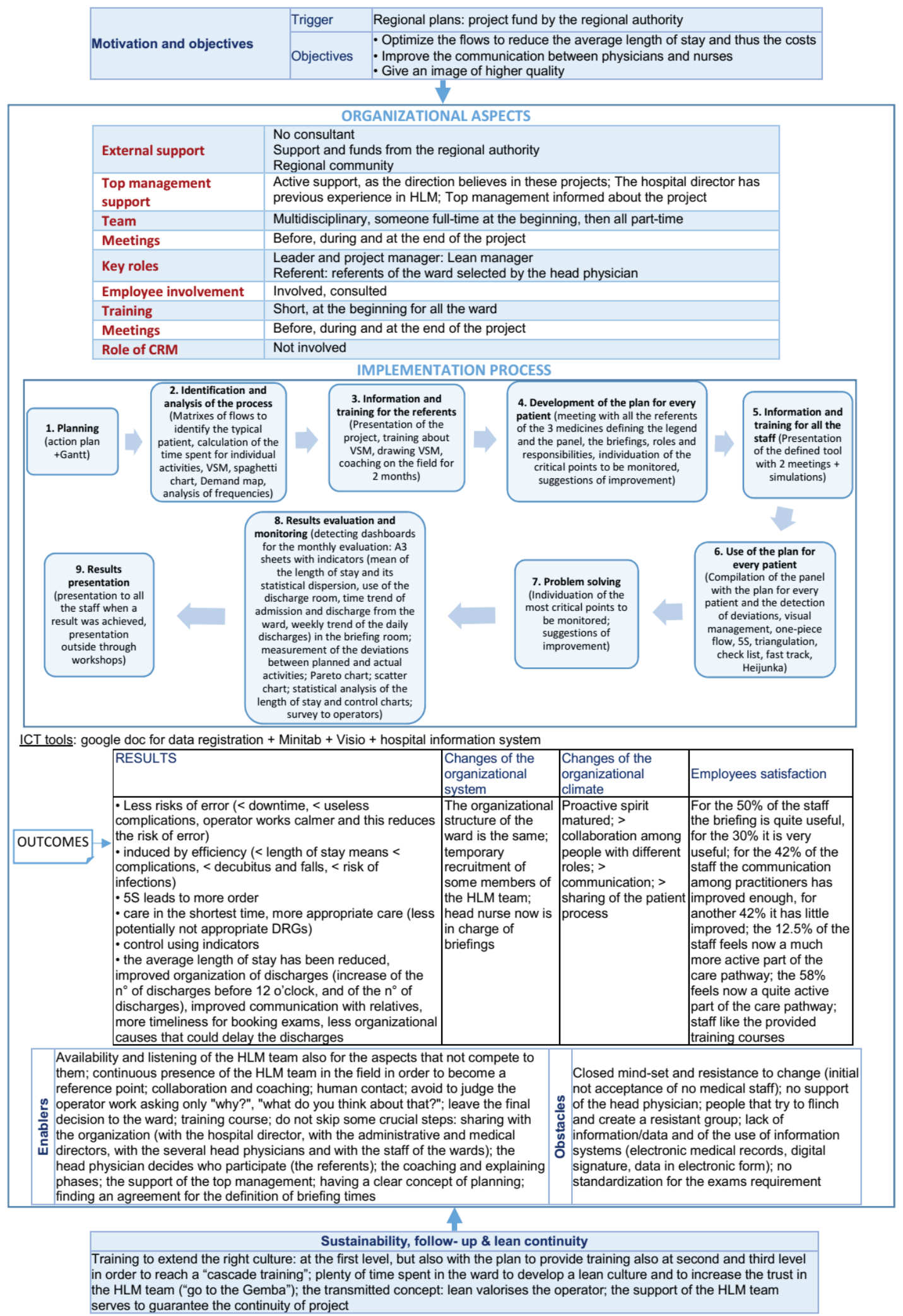

ISSN: 0718-2724. (http://jotmi.org)

Journal of Technology Management \& Innovation @ Universidad Alberto Hurtado, Facultad de Economía y Negocios. 
Fig. 3 Key characteristics of the "Lean \& Safety" project Beta.

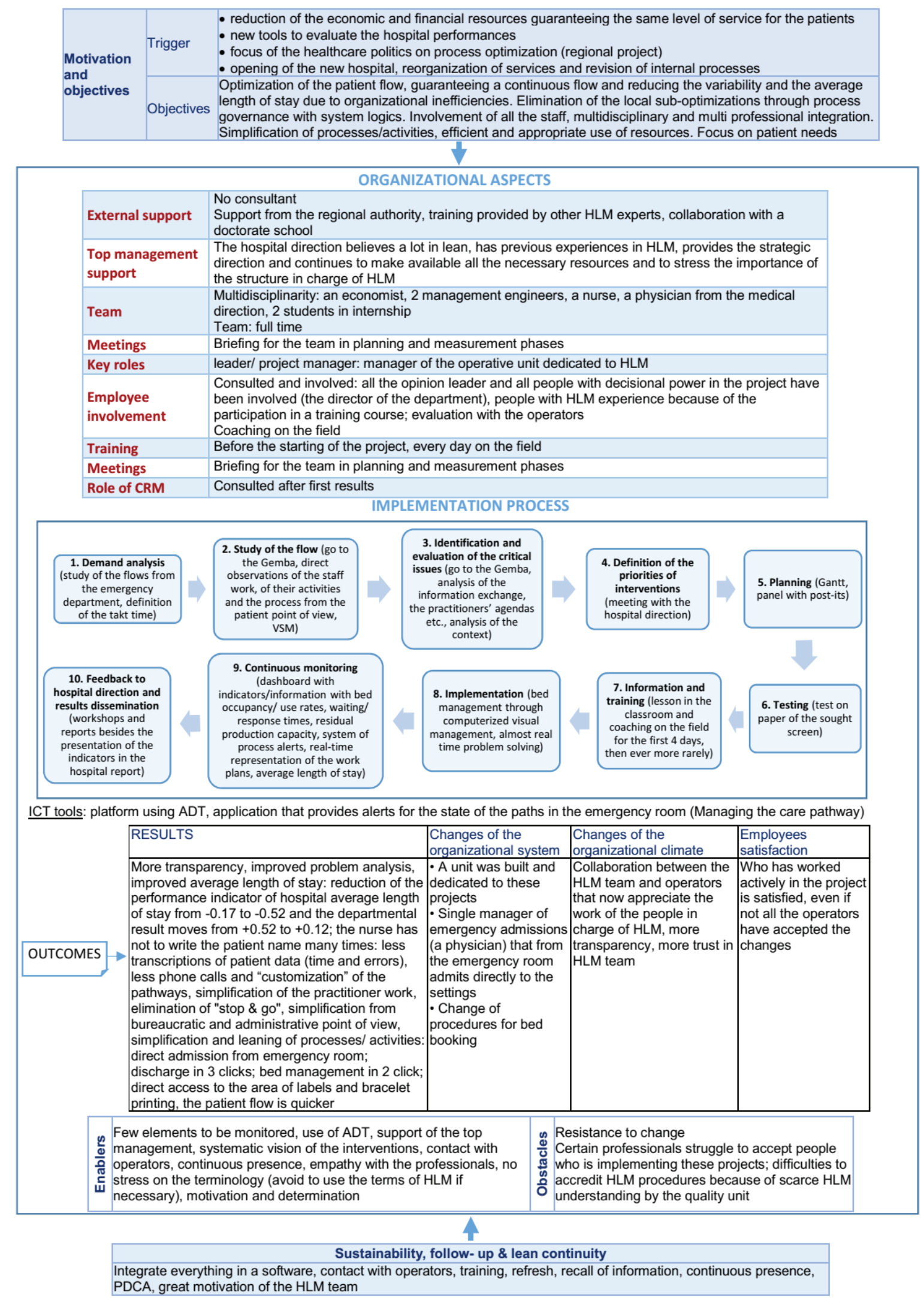

ISSN: 0718-2724. (http://jotmi.org)

Journal of Technology Management \& Innovation ( ) Universidad Alberto Hurtado, Facultad de Economía y Negocios. 
